\title{
Capacidade de Absorção e Canais de Interação Universidade- Empresa: uma Análise Empírica para Empresas no Rio Grande do Sul
}

\section{Absorption Capacity and Channels of Interaction between University and Firm: an Empirical Analysis for Firms in Rio Grande do Sul}

\author{
Andréia Cunha da Rosa* \\ André Luiz da Silva Teixeira** \\ Janaina Ruffoni*** \\ Márcia Siqueira Rapini* ** *
}

Resumo: O objetivo deste artigo é analisar de forma pioneira a interação entre as dimensões da Capacidade de Absorção (CA) da empresa, os canais de troca de informação e conhecimentos com as universidades e os resultados da inovação para a firma. A partir de informações coletadas de empresas localizadas no Rio Grande do Sul que interagiram com universidades e o uso do método de Componentes Principais Categóricos, foram identificadas especificidades das dimensões da CA de acordo com o canal utilizado pela empresa. Constatou-se que: (1) empresas que interagem via consultoria possuem maiores capacidades de assimilação; (2) quem interage via pesquisa conjunta tem maior capacidade de aquisição e exploração; (3) quem interage via canais ligados à "universidade empreendedora" não possui capacidades absortivas distintas das demais. Comprovou-se também que quem inova em produto e processo tem maior capacidade de assimilar, transformar e explorar o conhecimento externo.

Palavras-chave: Capacidade de absorção da firma. Canais de troca de conhecimento e informação. Interação universidade-empresa.

\begin{abstract}
The aim of this paper is to analyze the interaction between firms' absorptive capacity (AC) dimensions, the channels for information and knowledge exchange with university and the firms' innovations results. From information collected in firms located in Rio Grande do Sul that interacted with universities and the use of Categorical Principal Component's method to analyze the data it was possible to measure the dimensions of $\mathrm{AC}$ and relate them to the channels used by firms. It was found that:

\footnotetext{
* $\quad$ Mestre em Economia pela Universidade do Vale do Rio dos Sinos. Tutora em EAD na Unisinos. E-mail: andreiac@unisinos.br

** Mestre em Economia pela Universidade Federal de Minas Gerais (UFMG). Doutorando em Economia na UFMG.E-mail: ateixeira@cedeplar.ufmg.br

***: Doutor em Política Científica e Tecnológica pela Universidade Estadual de Campinas. Professora do Programa de Pós-Graduação em Economia da Universidade do Vale do Rio dos Sinos (Unisinos).E-mail: jruffoni@unisinos.br

**** Doutor em Economia da Indústria e da Tecnologia pela Universidade Federal do Rio de Janeiro. Professora do Centro de Desenvolvimento e Planejamento Regional (Cedeplar) e da Faculdade de Ciências Econômicas da Universidade Federal de Minas Gerais (UFMG).E-mail: msrapini@ cedeplar.ufmg.br
} 
(1) companies that interact through consulting have higher capacities of assimilation;

(2) firms that interact via joint research have greater acquisition and exploitation capabilities; (3) firms that interact by "entrepreneurial University" channels do not have different AC. We also found that firms who innovate in product and process have greater capacity to assimilate, transform and explore external knowledge.

Keywords: Firms' absorptive capacity. Channels of information and knowledge exchange. University-industry interactions.

JEL Classification: L25; O31.

\section{Introdução}

A interação de empresas com universidades e institutos de pesquisa (IUE) é apontada na literatura como uma importante fonte de conhecimento para o processo de inovação das empresas. As universidades podem contribuir para isso como: fonte de conhecimento de caráter mais geral, necessário para as atividades de pesquisa básica (NELSON, 1990), ou mais especializado, relacionado à área tecnológica da empresa (KLEVORICK et al., 1995); formação e treinamento de engenheiros e cientistas capazes de lidar com problemas associados ao processo inovador (ROSENBERG; NELSON, 1994); criação de novos instrumentos e de técnicas científicas (ROSENBERG, 1992) ou até de empresas nascentes (spin-offs) por pessoal acadêmico (ETZKOWITZ et al., 2000).

A IUE possibilita às empresas o desenvolvimento e o acesso a diversos resultados da pesquisa acadêmica e aos conhecimentos científicos e tecnológicos das universidades. Existem diferentes canais pelos quais as universidades podem transferir esses conhecimentos, desde os canais tradicionais (educação e pesquisa básica), até canais mais comerciais, como licenciamento, criação de spin-offs e patentes. Porém, não basta a universidade dispor de diversos tipos de conhecimentos, dos mais básicos aos mais complexos, para que os mesmos possam ser utilizados pela empresa. A empresa precisa ter capacidade para identificar, assimilar, transformar e explorar esse conhecimento. Essas capacidades compõem a chamada capacidade de absorção (CA), considerada determinante para a IUE (COHEN; LEVINTHAL, 1990; MEYER-KRAHMER; SCHMOCH, 1998).

Contudo, observa-se que a relação entre canais de transferência de conhecimento da IUE e CA ainda não está estruturada na literatura tanto teórica quanto empírica. Esta é a principal contribuição do artigo: analisar a relação entre as dimensões da CA da empresa e os canais de troca de informação e conhecimentos na IUE. Para tanto, utilizou-se dados de survey realizada para mensurar as dimensões da CA nas empresas localizadas no Rio Grande do Sul que interagem com universidades. Os dados foram analisados a partir do método de Componentes Principais Categóricos (CatPCA). Como resultado foram obtidos indicadores para 
cada dimensão da CA, relacionando-as com a inovação das empresas e os canais utilizados na IUE.

Ademais da introdução, o artigo possui mais quatro seções. A segunda apresenta uma discussão teórica sobre CA e canais de troca de informação e de conhecimento na IUE. A terceira apresenta a metodologia da coleta dos dados primários e o método de CatPCA utilizado. A quarta analisa os resultados e, na quinta, são apresentadas as considerações finais.

\section{Capacidade de Absorção da Empresa e Canais de Interação com Uni- versidade}

A seguir é apresentada inicialmente uma discussão teórica relativa à capacidade de absorção (CA), expondo-se a evolução do seu conceito e mensuração. Também são apresentados os principais canais de interação universidade-empresa (IUE) e suas possíveis articulações com as dimensões da CA.

\subsection{Capacidade de Absorção da Empresa}

Cohen e Levinthal $(1989,1994)$ argumentam que empresas que desenvolvem CA reduzem os custos de aquisição de conhecimentos externos e possuem maior acurácia na previsão de tendências tecnológicas, obtendo maiores vantagens de oportunidades emergentes, antes que seus concorrentes possam percebê-las. Cohen e Levinthal (1989) mencionam, ainda, formas de políticas públicas para incentivar o desenvolvimento da CA, como o apoio a formas de comercialização do conhecimento gerado em universidades e laboratórios de pesquisa.

Chen (2004) argumenta que empresas com um alto nível de CA possuem melhor compreensão e aproveitamento dos novos conhecimentos gerados em outras organizações que auxiliem suas atividades inovativas. Para Cohen e Levinthal (1990), a capacidade de absorção é única e específica da organização e, portanto, o conhecimento externo não pode ser comprado e integrado à sua rotina de maneira automática. Eles postulam o caráter dependente da trajetória da CA (path dependent), isto é, o seu desenvolvimento acontece por meio de um processo contínuo de aquisição de conhecimento pessoal e organizacional, somado ao aperfeiçoamento dos mecanismos e processos internos de articulação desse conhecimento ao longo do tempo.

Conforme Vega-Jurado, Gutiérrez-Gracia e Fernándes-de-Lucio (2008), a CA é influenciada pelo grau de complexidade do conhecimento, sendo que conhecimentos complexos requerem interações mais fortes entre os membros organizacionais enquanto que para conhecimentos mais simples essa interação não é tão requerida. Assim, tais autores contribuem com a literatura apresentando dois 
conceitos de capacidade de absorção: CA Científica e CA Industrial. A CA Científica refere-se à capacidade da empresa de absorver conhecimentos provenientes das universidades, institutos tecnológicos e eventos científicos. Mencionam que, quanto maior o número de funcionários da empresa com qualificações de ensino superior, mais fácil será para a empresa associar-se e acessar as bases de conhecimento de universidades. Já a CA Industrial é a capacidade da empresa de absorver o conhecimento proveniente de seus parceiros industriais, como clientes, concorrentes e fornecedores. Assim, o desenvolvimento da CA pode se dar de formas diferentes, pois se relaciona com habilidades específicas necessárias para a aquisição de cada tipo de conhecimento.

Murovec e Prodan (2009) complementam o trabalho acima, afirmando que a CA é específica ao conhecimento buscado, podendo ser "empurrada pela ciência" (science-push) ou "puxada pela demanda" (demand pull) e que esses diferentes tipos de CA podem influenciar a geração de inovações em produtos e processos. O primeiro tipo decorre do uso de conhecimento das universidades e institutos de pesquisa, enquanto o segundo relaciona-se com o uso de clientes, concorrentes e fornecedores como fonte de informação.

Uma das formas de ver a especificidade da CA é analisar sua multidimensionalidade. Cohen e Levinthal (1990) estabeleceram três dimensões que derivam do conceito de CA. A primeira é a habilidade da empresa de reconhecer o valor do novo conhecimento externo. A segunda é a capacidade de assimilar o novo conhecimento, internalizando-o. E a terceira dimensão diz respeito à capacidade de comercializar o novo conhecimento. Quanto mais experiência as organizações envolvidas tiverem na resolução de problemas semelhantes, mais fácil será para a empresa receptora encontrar uma aplicação comercial para o conhecimento recentemente assimilado. Portanto, quanto maior a similaridade de experiências entre as organizações envolvidas, mais fácil será o desenvolvimento da CA.

O aprofundamento do conceito de CA ocorre com Zahra e George (2002), diferenciando a CA em capacidade absortiva potencial e realizada. A CA potencial permite à empresa ser receptiva ao conhecimento externo, isto é, adquirir, analisar, interpretar e compreender este conhecimento, envolvendo as dimensões de aquisição e assimilação. Porém, o fato de uma empresa adquirir e avaliar o conhecimento externo não garante que ela consiga explorá-lo, pois isso depende da capacidade técnica da empresa (COHEN; LEVINTHAL, 1990; ZAHRA; GEORGE, 2002). Quanto maior for essa capacidade, maior será a compreensão, assimilação e beneficiamento/aproveitamento deste conhecimento externo. Zahra e George (2002) mencionam que a CA realizada reflete a capacidade da empresa em transformar e explorar o novo conhecimento, incorporando-o ao conhecimento prévio. Esta capacidade é determinada pelas dimensões de transformação e de exploração. 
Recentemente, Jiménez-Barrionuevo et al. (2011, p. 192) redefinem essa capacidade como a "capacidade relativa da organização para desenvolver um conjunto de rotinas organizacionais e processos estratégicos através do qual se adquire, assimila, transforma e explora os conhecimentos adquiridos externamente a fim de criar valor". Esta nova definição considera as quatro fases do desenvolvimento da CA estabelecidas por Zahra e George (2002), ampliando-as da seguinte forma: a capacidade de aquisição permite localizar, identificar, avaliar e adquirir conhecimento externo que é importante para o desenvolvimento de suas operações; a capacidade de assimilação possibilita analisar, classificar, processar, interpretar e, finalmente, internalizar e compreender o conhecimento externo; a capacidade de transformação facilita a transferência e combinação de conhecimento prévio com o conhecimento recém-adquirido ou assimilado, consistindo em adicionar ou eliminar conhecimentos e de interpretar e combinar com outros conhecimentos existentes na empresa. Por fim, a capacidade de exploração permite incorporar o conhecimento adquirido, assimilado e transformado nas operações e rotinas para a aplicação e uso, resultando na criação ou melhoria de novos produtos, sistemas, formas de organização e competências.

Quanto à mensuração da CA da empresa, devido à sua natureza intangível e à falta de consenso na literatura a respeito das dimensões que a compõem, não há uma "medida padrão" para mensurá-la (VERSIANI et al., 2010; FLATTEN, et al., 2011). Alguns estudos utilizam o PED como proxy (COHEN; LEVINTHAL, 1989; MANGEMATIN; NESTA, 1999), não incluindo suas várias dimensões e suas implicações para os diferentes resultados da empresa (CAMISÓN; FORÉS, 2010). No Brasil, alguns trabalhos que avaliaram a CA da firma utilizaram proxies para esta, como o tipo de fonte de informação buscada (BITTENCOURT; GIGLIO, 2013; NEGRI, 2006).

O presente estudo busca contribuir para essa discussão de mensuração da CA ao utilizar um instrumento de pesquisa de coleta de dados primários que considera os avanços apresentados pelos autores mencionados acima. Isso é apresentado na seção 3 do trabalho. Porém, este trabalho se diferencia dos demais, pois mensura tais dimensões da CA no contexto de interação universidade-empresa. Como destacado, a CA tende a apresentar especificidades de acordo com o tipo de conhecimento que a empresa busca, especialmente se busca conhecimentos provenientes de outras empresas ou de fontes acadêmicas, como as universidades. A próxima subseção discute as especificidades da CA em um contexto de interação com universidades, destacando como pode ser específica à forma como se dá essa interação. Em outras palavras, como que a CA pode ser específica ao canal de troca de conhecimento e informação com a universidade utilizado pela empresa. 


\subsection{Canais de Interação Universidade-Empresa e as Especificidades da Capacidade de Absorção}

A pesquisa oriunda das universidades raramente gera novas tecnologias, mas tem capacidade de potencializar as oportunidades tecnológicas das empresas. A IUE assume um papel cada vez mais importante, uma vez que é capaz de ampliar as possibilidades de aplicação dos resultados de pesquisa das universidades e pode resultar no aumento da capacidade das empresas de gerar inovações (NELSON, 1986). Nesse contexto, há um interesse crescente na literatura por compreender os fatores que estimulam e caracterizam as relações de interação entre a universidade e as empresas. ${ }^{1}$

A contribuição das universidades para o progresso tecnológico e econômico vem mudando ao longo do tempo. Até meados dos anos 1980, prevalecia a ideia linear acerca do processo inovativo, em que a principal contribuição das universidades para o progresso tecnológico era a geração de pesquisa básica (MOWERY; SAMPAT, 2006). Segundo Lundvall (2002), esse modelo perde força após os anos 1980, com estudos mostrando que tal linearidade não era observada na prática - e.g. Rosenberg (2006) - e reconhecendo outras formas das universidades favorecerem o progresso tecnológico. Por exemplo, para Brundenius, Lundvall e Sutz (2009), a principal forma para as universidades contribuírem para o processo inovativo em países em desenvolvimento é via formação de graduados e pós-graduados com capacidades para resolver problemas práticos e estabelecer interações com outros agentes, como as empresas. Já para Etzkowitz et al. (2000), as universidades poderiam agir como "fonte semeadora" de novas empresas, via parques tecnológicos e incubação de empresas. Segundo esses autores, a universidade deveria ser "empreendedora".

Atualmente, diversos trabalhos empíricos têm mostrado que a geração de pesquisa básica, formação de mão de obra ou incubação de empresas não são as únicas formas das universidades interagirem com as empresas. Tal interação pode acontecer através de variados canais, formais ou informais. Os canais mais reconhecidos na literatura são: contratos conjuntos de Pesquisa e Desenvolvimento (PED); mobilidade de recursos humanos (estudantes e acadêmicos); redes; difusão de informação através de publicações, conferências e internet; consultoria e treinamento; direito de propriedade; incubadoras e spin-offs (FUENTES; DUTRENIT, 2012). A seguir, busca-se relacionar, teoricamente, especificidades dos mecanismos de interação universidade-empresa - chamados canais - com idios-

$1 \quad$ Nos Estados Unidos, destacam-se os trabalhos de Klevorick et al. (1995) e de Cohen, Nelson e Walsh (2002). No Brasil, Suzigan, Albuquerque e Cario (2011) apresentam um amplo panorama das interações universidade-empresa. 
sincrasias da CA. Em outras palavras, busca-se observar como diferentes canais relacionam-se com diferentes capacidades absortivas.

Primeiramente, a literatura aponta que os canais de interação variam em termos da área do conhecimento, da tecnologia e do setor de atividades da empresa (KLEVORICK et al., 1995; COHEN; NELSON; WALSH, 2002). Eles podem ser agregados em diferentes categorias em termos do grau de formalidade, o grau de interação, a direção do fluxo de conhecimento e do potencial de se obter resultados aplicados (FUENTES; DUTRÉNIT, 2012). Dutrénit e Arza (2010) destacam que os mesmos variam de acordo com o respondente - se empresa ou universidade - e também em vista da motivação para a interação.

Para Arza (2010), as empresas podem interagir com universidades visando suas atividades de produção de curto prazo (solucionar problemas produtivos de curto prazo, como busca de conselhos e informações, realizar testes, controle da qualidade, etc.) ou para contribuir com suas estratégias de inovação de longo prazo (construção de capacidades, aumentar a capacidade de absorção, busca de parceiros para atividades de pesquisa que complementem ou substituam o PED). Portanto, se a forma como a interação ocorre depende das estratégias das empresas e a capacidade de absorção também é uma decisão estratégica destas, há um primeiro indício da relação canais e CA: diferentes estratégias levam a diferentes desenvolvimentos das capacidades absortivas e também a escolher diferentes canais para interagir, visando, inclusive, desenvolver tal capacidade.

Os canais utilizados também variam de acordo com características do Sistema Nacional de Inovação. Cohen, Nelson e Walsh (2002) investigam, através do Carnegie Mellon Survey, a influência do Setor Público de Pesquisa (universidades e laboratórios governamentais) nas atividades de PED industrial norte-americano. Por meio de análises descritivas, os autores identificam que os principais mecanismos de transmissão da pesquisa universitária foram publicações, encontros e conferências, contatos informais e, em menor proporção, via consultoria. Para poucas indústrias o licenciamento ou patente foram meios importantes de obtenção de informação. Ou seja, os principais canais estão relacionados com "ciência aberta", e, portanto, não mediados pelo mercado.

Eun (2009), analisando informações de pesquisa realizada com universidades e empresas na China, menciona que os canais de troca de informação e conhecimento mais importantes foram contratos formais de pesquisa, transferência de tecnologia por canais comerciais (patentes e licenciamentos), incubadoras e parques tecnológicos. O autor explica que a preferência das empresas chinesas por canais formais se dá pela incompletude do sistema legal chinês e pela limitada experiência na interação universidade-empresa. Tais acordos protegem os interesses e previnem contra o comportamento oportunista dos parceiros. 
Joseph e Abraham (2009), investigando a IUE na Índia, encontraram, via análises descritivas, os canais formais que foram os mais relevantes, como: contratos de pesquisa, projetos de PEB cooperativos, participação em redes que envolvem universidades, troca temporária de pessoal, parques científicos/ tecnológicos, empresas de universidades e spin-offs. ${ }^{2}$ Contudo, as universidades foram consideradas pouco importantes como fontes de informação para a inovação nas empresas. As empresas indianas consideram que possuem atividades de P\&D suficientes para inovar e a interação com universidades, quando presente, complementa este esforço. Por sua vez, as poucas empresas que colaboraram com universidades apresentaram-se mais inovadoras em produto.

Eom e Lee (2009) encontraram para a Coréia do Sul que os canais de troca de informação na IUE apresentam especificidades setoriais. Por exemplo, os autores sugerem que empresas de setores de alta tecnologia são mais ativas em gerar e absorver novos conhecimentos através de canais de informação que não envolvem a propriedade intelectual, isto é, os canais informais, educacionais e de contrato de pesquisa. Tais empresas, por serem mais intensivas em conhecimento, tendem a possuir maior capacidade de absorção (COHEN; LEVINTHAL, 1990). Sendo assim, empresas de diferentes setores, com diferentes estratégias competitivas e capacidades absortivas, tendem a buscar diferentes canais para interagir. Esses indícios serão explorados mais a frente.

Já para o Brasil, Castro, Teixeira e Lima (2014) realizaram um estudo semelhante ao anterior, observando que as atividades informais são importantes tanto para inovações de produto quanto de processo, enquanto as patentes e o licenciamento são relevantes apenas para a inovação de produto. ${ }^{3}$ Já Fernandes et al. (2010) ${ }^{4}$ identificaram que os canais mais relevantes declarados pelas empresas foram publicações, relatórios e conferências, contratos conjuntos de PEBD, contratação de recém graduados e canais informais de troca de informação. Os autores encontraram que os canais de fluxo bidirecional de conhecimento foram importantes tanto para as atividades produtivas de curto prazo quanto para a inovação nas empresas. Por sua vez, os canais de "serviços" (consultoria, treinamento, troca informal de informação) foram importantes para as atividades produtivas das empresas. Os canais comerciais (patentes, licenciamento, incubadoras e spin-offs) demonstraram pouca importância, sendo relevantes para as atividades produtivas

2 A relevância dos mecanismos institucionais como canais de troca de informação sugere que a interação universidade-empresa na Índia esteja sendo estimulada pela política de inovação.

3 Esses autores utilizam um modelo probit bivariado e a base de dados intitulada BR Survey (específica para a relação universidade-empresa) para avaliar como diferentes canais afetam as chances das empresas inovarem em produto e/ou em processo. Mesma técnica é empregada por Eom e Lee (2009), com uma base de dados similar para o caso sul-coreano.

4

Esses autores utilizam a base de dados intitulada como BR Survey, uma análise descritiva um modelo de regressão linear para explicar como diferentes canais afetam os benefícios da interação com universidades percebidos pelas empresas. 
de curto prazo das empresas. Portanto, a ideia destacada anteriormente de que diferentes objetivos estão atrelados com diferentes canais de interação - e, ainda hipoteticamente, com diferentes capacidades absortivas - também se verifica para o contexto brasileiro, foco do presente estudo.

Complementar a isso, a literatura aponta que empresas com maiores CAs buscam inovar mais, sendo mais proativas, visando aproveitar mais rapidamente oportunidades tecnológicas (BOSCH; VOLBERDA; BOER, 1999) e possuindo maiores capacidades para tal (COHEN; LEVINTHAL, 1990). Dessa forma, tais empresas tenderiam a buscar objetivos mais de longo prazo - como construções de capacidades - utilizando canais bidirecionais, como as pesquisas conjuntas (ARZA, 2010).

Além do uso de determinado canal estar relacionado com o objetivo da empresa ao buscar a interação, os canais de interação transmitem conhecimentos distintos. Fernandes et al. (2010) sugerem, baseando-se em Arza (2010), que os canais podem ser unidirecionais, quando o conhecimento flui apenas das universidades para as empresas, ou bidirecionais, quando há uma troca mútua de conhecimento. Cada um exige distintos esforços internos por parte da empresa para absorvê-los, ou seja, exigem diferentes CAs.

Já Fuentes e Dutrénit (2014) separam os canais de acordo com o tipo de conhecimento transferido. Destacam que conferências, trocas informais de informações e contratação de graduados transferem conhecimento tácito, ao passo que a interação através da contratação de PEBD ou licenciamento de tecnologia tende a transferir conhecimento codificado. Para Mangematin e Nesta (1999), canais 5 que transferem conhecimento mais codificado tendem a ser utilizados por empresas com menores CAs. Já empresas com maiores CAs tendem a obter tanto conhecimento codificado quanto tácito e a utilizar uma variedade de canais, como patentes, artigos e contratação de estudantes (MANGEMATIN; NESTA, 1999). Ademais, como salientado por Fernandes et al. (2010), canais como consultoria tendem a ser utilizados principalmente para resolução de problemas mais de curto prazo, ligados à produção. Logo, pode-se supor que eles transferem um conhecimento mais próximo ao que a empresa já possui. Por outro lado, canais ligados à pesquisa conjunta tendem a exigir esforços de ambos os atores e a estarem vinculados com a busca do novo, como a realização de inovações.

Dadas as considerações acima, é possível estabelecer uma conexão mais direta entre CA e canais de interação. Dado que a CA é específica ao tipo de conhecimento buscado pela empresa (MUROVEC; PRODAN, 2009; VEGA-JURADO; GUTIÉRREZ-GRACIA; FERNÁNDES-de-LUCIO, 2008) e que cada canal transfere um conhecimento distinto e exige esforços também específicos para absorvê-los,

5 Mangematin e Nesta (1999) não utilizam o termo canais, mas sim o termo "veículos". 
pode-se supor que diferentes formas de interação estão atreladas a diferentes capacidades absortivas. Esta é a hipótese central que norteia as análises seguintes.

Dois pontos devem ser salientados. Primeiramente, a relação entre canais e CA não é unilateral. Diferentes canais podem exigir diferentes capacidades absortivas, mas diferentes formas de interação podem contribuir para desenvolver essas capacidades também. Por exemplo, os canais de pesquisa conjunta, marcados pela colaboração entre os agentes, podem ser uma forma das empresas elevarem suas capacidades absortivas (GALINA; ALVES; VICENTIN, 2016), dado que tais canais de interação permitem o que Bishop, D'Este e Neely (2011) chamam de explorative learning. Este aprendizado está relacionado com atividades como a pesquisa, experimentação e descoberta, favorecendo especialmente a capacidade da empresa identificar novos conhecimentos e assimilá-los (i.e. favorece a CA potencial). Portanto, em termos teóricos, não se pode afirmar que há uma relação de causalidade única entre canais e CA.

Por fim, é válido destacar também que, embora essa capacidade seja apontada como um dos determinantes da interação universidade-empresa (MEYER-KRAHMER; SCHMOCH, 1998, p. 847), não foi identificado nenhum estudo para o Brasil que tenha analisado a relação entre as dimensões da CA e os canais de troca de informação e conhecimentos na interação universidade-empresa, sendo esta a principal contribuição deste artigo. A seção seguinte traz a metodologia empregada para investigar tal relação, seguindo com as análises dos resultados.

\section{Metodologia}

Os dados analisados neste estudo foram retirados de fontes secundária e primária. Os dados de fonte secundária foram coletados junto ao Censo de 2010 do Diretório dos Grupos de Pesquisa do CNPq, referentes à interação dos grupos de pesquisa com o setor produtivo. Para o Rio Grande do Sul, naquele Censo, foram identificadas 611 empresas que interagiam com 462 grupos de pesquisa, podendo haver grupos com interação com mais de uma empresa. Um subconjunto destas empresas, detalhado a seguir, foi a amostra da pesquisa. Para o tratamento dos dados foi utilizado o método de Componentes Principais Categóricos (LINTING et al., 2007; MEULMAN; VAN DER KOOIJ; HEISER, 2004). Esta seção apresenta este método e detalha a coleta dos dados primários.

\subsection{Coleta de Dados Primários}

Foi realizado um survey com empresas informadas pelos líderes dos grupos de pesquisa no Censo de 2010 do Diretório de Grupos de Pesquisa (DGP) do CNPq que realizaram interações com estes. Optou-se por focar nas empresas que intera- 
giam com grupos das áreas de Engenharia Mecânica, de Materiais e Metalúrgica das Universidades do RS, visto que a área das Engenharias nesse estado é que mais possui grupos que declararam ter interação com empresas. A população da pesquisa era de 71 empresas privadas localizadas nesse estado de pequeno, médio e grande porte, conforme classificação do SEBRAE. Os respondentes foram identificados previamente por meio de contato telefônico e eram profissionais envolvidos com atividades de inovação das empresas e que participavam (ou tinham participado) do processo de interação com a(s) universidade(s).

O instrumento elaborado para a coleta dos dados foi submetido à avaliação na etapa de pré-teste, na qual foram entrevistadas 13 empresas. O questionário estruturado foi organizado em três partes: elementos da CA, características da interação universidade-empresa e informações a respeito da atividade de inovação da empresa. Para capturar as respostas referentes à CA foi utilizada uma escala do tipo Likert de concordância de 5 pontos, seguindo sugestões de estudos anteriores como Jiménez-Barrionuevo et al. (2011) e Camisón e Forés (2010). Os Quadros 2 e 3, no Apêndice, apresentam as questões utilizadas nesse survey para mensurar as dimensões da Capacidade de Absorção. ${ }^{6}$

Após a validação do instrumento, ${ }^{7}$ foi aplicado o questionário em toda a população de empresas. O total de respostas foi de 32 , representando $45 \%$ da população. Para o presente estudo são utilizadas 24 empresas, pois as 8 empresas restantes não responderam pelo menos uma das questões sobre a CA, tendo sido, portanto, excluídas da análise. A Tabela 1 sintetiza a distribuição setorial da amostra.

$6 \quad$ O questionário completo encontra-se em Rosa (2013).

7 A análise de confiabilidade da CA foi obtida através do cálculo do coeficiente alfa de Cronbach (HAIR et al., 2005). Os resultados indicam que os valores do alfa de Cronbach gerados para cada dimensão da CA ficaram acima de 0,6, sendo possível afirmar que as dimensões da escala da CA possuem consistência interna. 
Tabela 1- Perfil setorial da amostra

\begin{tabular}{l|l}
\hline Setor & $\mathbf{N}^{\mathbf{o}}$ obs. \\
\hline Fabricação de produtos de metal, exceto máquinas e equipamentos & 3 \\
Fabricação de veículos automotores, reboques e carrocerias & 3 \\
Metalurgia & 2 \\
Fabricação de máquinas e equipamentos & 5 \\
Fabricação de produtos de borracha e de material plástico & 3 \\
Fabricação de produtos químicos & 3 \\
Eletricidade, gás e outras utilidades & 1 \\
Serviços & 1 \\
Tecnologia da Informação & 1 \\
Não foi possível determinar & 2 \\
\hline Total & $\mathbf{2 4}$ \\
\hline
\end{tabular}

Fonte: Elaboração própria a partir dos dados coletados por Rosa (2013).

Quanto ao porte, 41,6\% são médias empresas (entre 100 e 400 empregados), 37,5\% são de grande porte (acima de 500 empregados) e as demais são empresas pequenas com menos de 100 empregados. Um maior detalhamento dessa base de dados pode ser encontrado em Rosa (2013). A seguir, apresenta-se o tratamento desses dados.

\subsection{Tratamento dos Dados}

Esta subseção apresenta inicialmente o método utilizado para tratamento dos dados, prosseguindo com detalhes sobre a construção dos indicadores.

\subsubsection{Método de Componentes Principais Categóricos}

O método de Componentes Principais Categóricos (CatPCA) é considerado o análogo não linear ao método de Componentes Principais linear (PCA). Assim como o PCA, o CatPCA também busca reduzir um grande número de variáveis em um número menor de variáveis não correlacionadas, chamadas componentes principais, visando minimizar a perda de informação. Porém, o CatPCA tem como uma de suas vantagens possibilitar a análise de dados categóricos ordinais (como aqueles mensurados pela escala Likert) e das relações não lineares entre as categorias e entre outras variáveis. É uma técnica propícia para analisar dados em que o número de variáveis seja superior ao número de observações (LINTING et al., 
2007; MEULMAN; VAN DER KOOIJ; HEISER, 2004). ${ }^{8}$ Portanto, é uma ferramenta útil para as características dos dados utilizados.

Nesse método, cada valor observado de uma variável ordinal é considerado uma categoria. Através do processo de optimal quantification, ${ }^{9}$ cada categoria é convertida em um valor numérico através de uma função não linear, transformando as variáveis categóricas em variáveis quantificadas. A partir dessas variáveis quantificadas, o método maximiza a soma dos $P$ maiores autovalores da matriz de correlação entre as variáveis quantificadas, sendo $P$ o número de dimensões escolhidas para a solução. A soma desses autovalores, dividida pelo número de variáveis, fornece a variância total explicada por essas dimensões (uma das medidas de qualidade do ajuste final). A variância explicada por cada dimensão e por cada variável quantificada separadamente é igual ao quadrado do component loading. Esse component loading é a correlação entre as variáveis transformadas e os componentes principais em uma particular dimensão. A consistência interna desses componentes é determinada pelo alfa de Cronbach, sendo este também uma medida de qualidade do ajuste final. Maiores detalhes podem ser encontrados em Linting et al. (2007) e Meulman, Van der Kooij e Heiser (2004).

\subsubsection{Construção dos Indicadores}

Foram utilizados quatro blocos de variáveis, cada um correspondendo a uma dimensão da CA. Essa divisão em quatro dimensões é sugerida teoricamente por Zahra e George (2002) e Jiménez-Barrionuevo et al. (2011) e validada empiricamente por Flatten et al. (2011) e Camisón e Forés (2010), por exemplo. Para cada bloco foi realizada uma análise de CatPCA, visando obter indicadores para cada dimensão. ${ }^{10}$ Cada bloco era composto por 7 variáveis categóricas ordinais, com 5 categorias cada, conforme escala Likert utilizada na pesquisa survey ( 1 equivale a "Discordo totalmente" e 5 a "Concordo totalmente"). Para todas essas análises foi possível a construção de apenas um indicador, tornando a interpretação mais objetiva e sem incorrer em grandes perdas de informação. Esse indicador está padronizado (com média zero e variância 1), de modo que valores positivos indicam capacidade superior à média e valores negativos, capacidades inferiores à média. A Tabela 2 apresenta as informações básicas para cada indicador. Os components loadings para cada análise encontram-se no Apêndice (Tabelas 6, 7, 8 e 9).

$8 \quad$ Essa técnica também permite a análise de base de dados compostas tanto por dados categóricos (nominais e/ou ordinais) como numéricos. Maiores detalhes são apresentados por Linting et al. (2007)

9 Para os diversos processos de optimal quantification, ver Linting et al. (2007).

10 Outra opção seria realizar apenas uma análise, com todas as dimensões de uma vez. Porém, isso geraria indicadores não correlacionados para as dimensões da $\mathrm{CA}$, o que não condiz com a literatura, como Zahra e George (2002). 
Tabela 2 - Informações básicas sobre os indicadores construídos para as 4 dimensões da Capacidade de Absorção

\begin{tabular}{l|c|c|c|c}
\hline $\begin{array}{c}\text { Qualidade } \\
\text { do ajuste dos } \\
\text { indicadores }\end{array}$ & Aquisição & Assimilação & Transformação & Exploração \\
\hline $\begin{array}{l}\text { \% da Variância } \\
\text { explicada }\end{array}$ & 54,157 & 74,955 & 75,189 & 70,745 \\
$\begin{array}{l}\text { Alfa de } \\
\text { Cronbach }\end{array}$ & 0,859 & 0,946 & 0,945 & 0,931 \\
\hline
\end{tabular}

Fonte: Elaboração própria a partir de Rosa (2013).

Como observado na Tabela 2, o indicador construído para analisar a capacidade de aquisição é o que explica a menor parcela da variância total, quando comparado com os demais indicadores construídos. Assim, são necessárias algumas observações sobre a construção desse indicador.

Primeiramente, além dessa análise para apenas um indicador para a capacidade de aquisição, foi observada a possibilidade de utilizar dois indicadores para essa dimensão da CA. O uso de dois indicadores explicaria 73,5\% da variância total (51\% pelo indicador 1 e 22,5\% pelo indicador 2). Porém, enquanto o alfa de Cronbach se mantém elevado para o primeiro indicador $(0,84)$, ele é igual a 0,43 para o segundo indicador, apresentando baixa consistência interna. Ao observar os components loadings para dois indicadores, nota-se que o segundo indicador seria representado apenas pela variável referente à cooperação com centros de PED (q1_7). Essa variável foi a única que apresentou component loading superior para o segundo indicador. ${ }^{11}$ As outras seis variáveis utilizadas para explicar a capacidade de aquisição apresentaram components loadings superiores para o primeiro indicador. ${ }^{12}$ Assim, a adoção de apenas um indicador para explicar a capacidade de aquisição é justificado pelo fato de este estar fortemente correlacionado (valores elevados de components loadings) com seis das sete variáveis utilizadas para mensurar a capacidade de aquisição ao mesmo tempo em que apresenta elevada consistência interna.

11 Vale lembrar que esse component loading indica a correlação entre a variável em questão e o indicador gerado. Quanto maior o component loading, maior a correlação.

12 A especificidade da cooperação com centros de PEBD como medida de capacidade de aquisição pode ser objeto de próximos estudos. 


\section{Análise dos Dados}

A análise dos dados foca em duas relações. A primeira analisa a proposição conhecida de que as empresas com maior nível de capacidade de absorção (CA) são mais inovadoras (CHEN, 2004; COHEN; LEVINTHAL, 1989). Já a segunda busca encontrar indícios de como diferentes dimensões da CA podem se relacionar com diferentes formas de interação (i.e., canais de interação). Para ambas as análises, as diferenças entre os grupos são testadas através de testes t de média, tanto com variâncias iguais quanto variâncias distintas. Adota-se um nível de significância de $10 \%$, devido ao tamanho pequeno da amostra. Os resultados são considerados "robustos" quando ambas as análises são significativas.

Porém, é importante discutir inicialmente a presença de um outlier nessa base de dados. Essa empresa respondeu os menores valores na escala Likert ( 1 ou 2) para praticamente todas as questões sobre a $C A$, inovou apenas em processo e interagiu apenas através de pesquisa encomendada. A subseção seguinte discute sua manutenção na base de dados.

\subsection{Manutenção do Outlier}

Para discutir a manutenção ou não do outlier nas análises, os indicadores são construídos novamente sem a presença destes. A Tabela 3 compara a qualidade do ajuste entre as análises com e sem o outlier. 
Tabela 3 - Comparação entre as análises CatPCA com ou sem o outlier.

\begin{tabular}{c|c|c|c}
\hline \multicolumn{1}{c|}{ Dimensão } & Qualidade do ajuste & $\begin{array}{c}\text { Com } \\
\text { outlier }\end{array}$ & $\begin{array}{c}\text { Sem } \\
\text { outlier }\end{array}$ \\
\hline \multirow{2}{*}{ Aquisição } & \% da variância & 54,157 & 40,732 \\
& Alfa de Cronbach & 0,859 & 0,7 \\
\cline { 2 - 4 } Assimilação & \% da variância & 75,638 & 60,396 \\
& Alfa de Cronbach & 0,946 & 0,891 \\
\cline { 2 - 4 } Transformação & \% da variância & 75,189 & 50,183 \\
& Alfa de Cronbach & 0,945 & 0,835 \\
\cline { 2 - 4 } Exploração & \% da variância & 70,745 & 61,802 \\
& Alfa de Cronbach & 0,931 & 0,897 \\
\hline
\end{tabular}

Fonte: Elaboração própria a partir de Rosa (2013).

Observa-se que, em todas as dimensões, os indicadores construídos sem a presença do outlier explicariam uma menor porcentagem da variância e apresentariam menor consistência interna. Ademais, a dimensão da capacidade de aquisição exigiria a utilização de dois indicadores, explicando 66,8\% da variância, o que dificultaria sua interpretação. Portanto, em geral, a retirada do outlier da amostra geraria perda de informação para o estudo. Logo, optou-se pela sua manutenção, mas não serão interpretados casos em que este estaria presente, dado o tamanho limitado da amostra e a distorção provocada por este na média.

\subsection{Capacidade de Absorção e Inovação}

A importância da capacidade de absorção (CA) da empresa para alavancar seu desempenho inovativo tem sido apontada na literatura por diversos autores (COHEN; LEVINTHAL, 1989, 1990, 1994; CHEN, 2004; MUROVEC; PRODAN, 2009). A Tabela 4 apresenta a relação entre as dimensões da CA das empresas e as inovações implementadas por estas. Para isso são calculadas as médias dos indicadores para cada dimensão e para cada tipo de inovação realizada. Nas comparações estatísticas foram realizados testes $t$ unicaudais, dado que a hipótese é de que quem inova tem maior CA do que quem não inova. ${ }^{13}$

13 Não foram realizados testes $t$ comparando quem inovou só em produto com os demais grupos, pois apenas três empresas realizaram apenas essa inovação. 
Tabela 4 - Média das dimensões da CA de acordo com a inovação implementada pela empresa

\begin{tabular}{l|c|c|c|c|c}
\hline Inovação & Aquisição & Assimilação & Transformação & Exploração & $\begin{array}{c}\mathbf{N}^{\circ} \\
\text { obs. }\end{array}$ \\
\hline $\begin{array}{l}\text { Nenhuma } \\
\text { inovação }\end{array}$ & 0,156 & $-0,220$ & 0,118 & $-0,454$ & 5 \\
$\begin{array}{l}\text { Só inovou } \\
\text { em }\end{array}$ & 0,387 & 0,230 & 0,130 & 0,143 & 3 \\
produto & & $\mathbf{0 , 3 5 6}$ & $\mathbf{0 , 2 7 7}$ & $\mathbf{0 , 4 0 4}$ & 14 \\
$\begin{array}{l}\text { Inovou } \\
\text { em } \\
\text { produto e } \\
\text { processo }\end{array}$ & 0,179 & & & & \\
\hline
\end{tabular}

Fonte: Elaboração própria a partir dos dados coletados por Rosa (2013).

Primeiramente, pode-se destacar a capacidade de exploração. Esta é entendida como as habilidades e rotinas da empresa que a permitem gerar novos produtos e processos a partir da incorporação do novo conhecimento às suas operações (COHEN; LEVINTHAL, 1990; ZAHRA; GEORGE, 2002). Essa definição é corroborada pela análise anterior, na qual empresas que inovaram tanto em processo quanto em produto apresentaram uma média para tal capacidade estatisticamente superior à média das empresas que não inovaram, tanto considerando variâncias iguais quanto distintas. ${ }^{14}$

Para as capacidades de assimilação e transformação, o comportamento é similar. As empresas que inovaram em produto e em processo foram as que apresentaram as maiores médias para essas capacidades, seguidas pelas inovadoras em produto. Porém, é interessante notar que a diferença entre inovadores em produto e processo vis a vis não inovadores quanto à capacidade de transformação é relativamente baixa quando comparada com a capacidade de assimilação, ainda que tal diferença tenha sido significativa para ambas as capacidades..$^{15}$ Todorova e Durisin (2007) sugerem que a capacidade de transformação pode não ser essencial para inovar vis a vis a capacidade de assimilação caso o conhecimento absorvido pela empresa seja similar ao conhecimento já possuído por ela, pois não exigiria uma reconfiguração da base de conhecimento, i.e., não exigiria elevada capacidade de transformar, mas sim de assimilar. Dessa forma, tal resultado seria reflexo de idiossincrasias da amostra, pois esta é formada por empresas que interagem com grupos de pesquisa das áreas de engenharias (mecânica, de materiais e

14 Para variância igual, a significância foi de 1\%.

15 Para a capacidade de assimilação, se considerar a variância distinta entre os dois grupos, o p-valor obtido foi de 0,1092, muito próximo ao nível de significância escolhido (10\%). Já para variâncias iguais, o p-valor foi de 0,0103. 
metalúrgica), em que o conhecimento obtido para inovar tende a ser mais aplicado e mais próximo ao conhecimento já possuído pela empresa, exigindo maiores capacidade para assimilá-lo. Portanto, há indícios, ainda que limitados, de que a interação com grupos de pesquisa de diferentes áreas do conhecimento pode exigir capacidades absortivas distintas por parte das empresas. Para o caso brasileiro, Carolo (2011) destaca também os diferentes estágios de desenvolvimento da ciência no país. As áreas de Engenharia, por exemplo, são recentes e há uma evidente complementaridade entre pesquisa básica e aplicada de forma que o desenvolvimento de projetos cooperados impacta também no estoque de conhecimento. Isso não será analisado neste trabalho, podendo ser objeto de estudos futuros.

Já para a capacidade de aquisição, a maior média foi apresentada pelas empresas que inovaram somente em produto, seguidas pelas empresas inovadoras em produto e em processo. Nessa dimensão, a diferença entre inovadoras de produto e processo e não inovadoras também não é elevada e não foi significativa, tanto para variâncias iguais quanto para diferentes. Isso reflete, possivelmente, a especificidade da amostra discutida anteriormente e o fato de serem empresas que já interagiram, ou seja, já identificaram o grupo de pesquisa e conhecimento relevantes.

Enfim, pode-se dizer que as empresas que inovam em produto e em processo tendem a ter uma capacidade de absorção superior às demais, seja em termos de capacidade potencial (principalmente de assimilação) ou capacidade realizada (transformação e exploração), corroborando a literatura. Ao mesmo tempo, as especificidades da amostra (empresas que já interagem com grupos de pesquisa de engenharia) podem explicar a menor importância da capacidade de aquisição e de transformação para inovar.

\subsection{Capacidade de Absorção e os Canais de Interação Universidade-Empresa}

Essa subseção apresenta as relações identificadas entre as dimensões da CA da empresa e os diferentes canais utilizados por esta para interagir com universidades. Para tornar possiveis as comparações estatísticas entre quem utilizou e quem não utilizou determinado canal, optou-se por uma agregação ex-ante, tendo em mente os diferentes papéis exercidos pela universidade. O Quadro 1 mostra tal agregação. 
Quadro 1 - Agregação dos canais de transferência de informação e conhecimento

\begin{tabular}{|c|c|}
\hline Canais & Agregação \\
\hline $\begin{array}{c}\text { Publicações e relatórios técnicos } \\
\text { Conferências } \\
\text { Cursos e treinamento } \\
\text { Contratacão de graduados ou pós-graduados }\end{array}$ & Canal tradicional \\
\hline $\begin{array}{c}\text { Consultoria } \\
\text { Pesquisa conjunta }\end{array}$ & $\begin{array}{c}\text { Consultoria } \\
\text { Pesquisa Conjunta }\end{array}$ \\
\hline $\begin{array}{c}\text { Licenciamento de tecnologia } \\
\text { Patentes } \\
\text { Incubadora } \\
\text { Parques científicos e tecnológicos }\end{array}$ & Empreendedor \\
\hline
\end{tabular}

Fonte: Elaboração própria.

Essa agregação reflete tanto questões teóricas quanto questões empíricas. Teoricamente, essa agregação permite captar como os diferentes papéis das universidades estão atrelados às dimensões da CA. São diferenciados os canais ligados ao papel dito tradicional - como formação de mão de obra e divulgação científica - daqueles atrelados à missão mais recente da universidade, vinculada a um papel empreendedor, em que esta passa a agir mais ativamente na criação e fomento de empresas, via incubadoras, e na comercialização de conhecimentos e tecnologias, via licenciamento de patentes (ETZKOWITZ et al., 2000).

Essa agregação também permite observar diferenças entre os canais consultorias e pesquisa conjunta. Apesar de ambos transferirem um conhecimento mais tácito (FUENTES; DUTRÉNIT, 2014), o primeiro é considerado um canal unidirecional (da universidade para empresa) que não exige elevados esforços por parte das empresas para absorvê-lo e que se relaciona com objetivos de curto prazo, como elevar sua capacidade produtiva. Enquanto isso, o segundo é relacionado com objetivos de longo prazo - e.g. desenvolver capacidades inovativas - e exige maiores esforços por parte das empresas para absorver o conhecimento compartilhado (ARZA, 2010; FERNANDES et al., 2010). Dado que tais canais estão atrelados a diferentes objetivos e exigem diferentes esforços por parte das empresas, possivelmente estão relacionados a diferentes dimensões da CA.

Por fim, essa agregação foi também adotada por motivos empíricos. Dada a necessidade de testar se há diferenças estatísticas entre quem usa determinado canal e quem não usa, a agregação permite um número maior de empresas para cada caso. Explicitamente sobre o canal tradicional, sua agregação merece escla- 
recimentos. Inicialmente, a divisão se dava entre "ciência aberta" (publicações, relatórios técnicos e conferências) e "educação" (cursos, treinamento e contratação de mão de obra), porém, foi observado que, das 24 empresas, 21 usaram ou ciência aberta ou educação. Dessas 21 empresas, 10 usaram ambos os canais. Portanto, a análise separada entre ciência aberta e educação não se mostrou viável e poderia levar a equívocos na sua interpretação.

Contudo, essa agregação resultou em uma limitação: apenas três empresas não utilizaram canais tradicionais na interação. Portanto, para dar transparência às análises, as médias apresentadas na Tabela 5 foram calculadas apenas para as empresas que utilizaram os canais tradicionais para interagir. Os valores destacados em negrito na tabela referem-se a casos em que a média para quem usou determinado canal foi superior, estatisticamente, à média de quem não o usou. ${ }^{16}$

Tabela 5 - Média das dimensões da Capacidade de Absorção entre as empresas que interagiram através de canais tradicionais e combinaram-nos com determinado canal

\begin{tabular}{l|c|c|c|c|c}
\hline \multicolumn{1}{c|}{ Canal } & Aquisição & Assimilação & Transformação & Exploração & $\begin{array}{c}\mathbf{N} \mathbf{N}^{\mathbf{0}} \\
\text { Obs. }\end{array}$ \\
\hline $\begin{array}{l}\text { Consultoria } \\
\text { Pesquisa }\end{array}$ & 0.312 & $\mathbf{0 . 3 4 7}$ & 0.256 & 0.319 & 11 \\
$\begin{array}{l}\text { conjunta } \\
\begin{array}{l}\text { Empreen- } \\
\text { dedor }\end{array}\end{array}$ & $\mathbf{0 . 3 6 1}$ & 0.310 & 0.223 & $\mathbf{0 . 4 2 0}$ & 10 \\
\hline
\end{tabular}

Fonte: Elaboração própria a partir dos dados obtidos por Rosa (2013).

Pelas estimativas acima, nota-se que cada canal está atrelado a dimensões distintas da capacidade de absorção. As empresas que utilizam o canal consultoria se diferenciam das demais principalmente quanto à capacidade de assimilação. Já as empresas que utilizam pesquisa conjunta se diferenciam das demais especialmente quanto à capacidade de aquisição e de exploração. Já as empresas que se valem de canais empreendedores não apresentaram diferenças significativas perante as demais empresas que interagem via outros canais. Essas diferentes relações entre dimensões da CA e canais podem ser reflexo tanto de especificidades de cada canal quanto da amostra e do contexto nacional. Isso é discutido a seguir.

Sobre a consultoria, se, por um lado, ela reflete a demanda por insumos acadêmicos pouco sofisticados, voltados a pequenas melhorias ou adaptações de curto prazo no processo produtivo (ARZA, 2010), por outro é um canal tradicionalmente utilizado pelas empresas brasileiras para evitarem a burocracia das

16 Foram testes unicaudais, considerando a hipótese de que quem usa determinado canal tem uma média superior a quem não usa. 
universidades. Burcharth (2011) mostra como as empresas podem se valer desse canal para assimilar conhecimentos externos. Analisando o caso de uma empresa A do setor de mineração que buscava produzir localmente uma tecnologia importada via parceria com outra empresa $B$, a autora sugere que a empresa $A$ se valeu de consultorias com pesquisadores universitários para conseguir interpretar e analisar os resultados provenientes de pesquisas e testes realizados na parceria com a empresa B. Assim, a empresa utilizou o canal de consultoria para compreender e internalizar os conhecimentos gerados nas parcerias com outras empresas, ou seja, a consultoria permitiu à empresa elevar sua capacidade de assimilação (JIMÉNEZ-BARRIONUEVO et al., 2011). Essa maior importância do canal consultoria para a capacidade de assimilação também pode ser devida às características da amostra, a qual é formada por empresas que interagem com grupos da engenharia, ou seja, o produto da consultoria envolve conhecimentos próximos da base produtiva da empresa, exigindo maior capacidade de assimilação ao invés de transformação (TODOROVA; DURISIN, 2007). Portanto, a consultoria, além de se voltar para pequenas melhorias ou objetivos muito específicos, também transferiria um conhecimento mais similar ao que a empresa possui e, portanto, demandaria mais assimilação vis a vis às demais capacidades.

Já a pesquisa conjunta é um canal bidirecional, o qual exige maiores esforços por parte das empresas e estaria relacionado com objetivos de longo prazo (ARZA, 2010). Nesse sentido, para que a empresa consiga definir uma parceria na qual ela despenderá maiores esforços, ela necessita identificar e valorar com maior clareza o conhecimento externo, isto é, ela necessita de maiores capacidades de aquisição que as empresas que utilizam outros canais. Por outro lado, tal cooperação pode ter permitido à empresa criar sua rede de contatos, favorecendo a capacidade de identificar e adquirir o conhecimento externo. Já quanto à dimensão da exploração, duas interpretações são possíveis. Pode-se sugerir que a cooperação na pesquisa permitiu à empresa redefinir suas rotinas, aprimorando sua capacidade para explorar o conhecimento externo ou, dado que a empresa possui maior capacidade para explorar conhecimentos externos, ela buscou cooperar e não apenas interagir via canais unidirecionais.

Por fim, sobre os canais relacionados ao papel empreendedor, não foram identificadas diferenças entre as empresas que os utilizaram e as empresas que usaram outros canais. Inclusive, esse canal foi o que apresentou a menor capacidade de aquisição entre os demais canais, o que pode ser explicado pela pouca idade das empresas eventualmente envolvidas. A capacidade realizada (de exploração e transformação) ainda está sendo construída e, por estar muito próxima da universidade e dos pesquisadores, a capacidade de aquisição não precisa ser muito alta. Muitas empresas são criadas por pesquisadores ou pós-graduados ou têm a super- 
visão direta de um pesquisador sênior, o que favorece a identificação e valoração dos conhecimentos relevantes.

Cabe ressaltar que as empresas respondentes pertencem a distintos setores (ver Tabela 1), demandando diferentes tipos de conhecimentos das universidades para seus esforços inovativos internos. As interações, por sua vez, foram com grupos de pesquisa de áreas de engenharia mais tradicionais, engenharia mecânica, de materiais e metalúrgica, sugerindo que as interações possam ter se dado para a solução de gargalos relacionados ao processo produtivo. Tais gargalos produtivos já haviam sido destacados por Rosenberg (1976) e sistematizados por Klevorick et al. (1995) como importantes fontes de oportunidades tecnológicas futuras para as empresas. Porém, diferentemente do contexto norte-americano, no qual estas são fontes internas às empresas, no Brasil, as empresas não dispõem de toda a capacidade interna para solucionar os problemas, buscando fora, nas universidades, a solução.

\section{Considerações Finais}

O presente estudo relaciona as dimensões da capacidade de absorção (CA), os canais de interação da empresa com as universidades e os resultados em termos de inovação. A partir de informações levantadas em pesquisa empírica com empresas do Rio Grande do Sul e a aplicação da técnica de Componentes Principais Categóricos (CatPCA), foram estimados indicadores para cada dimensão da CA (aquisição, assimilação, transformação e exploração).

Foram realizadas duas análises. A primeira testou a hipótese de que empresas que inovam possuem maiores CAs. Ainda que conhecida na literatura, há poucos esforços empíricos para mensurar a CA para países em desenvolvimento, sendo esta uma contribuição relevante do presente trabalho. Através de testes $t$ de médias, mostrou-se que empresas que inovam em produto e em processo possuem maiores capacidades de assimilação, transformação e exploração em comparação com empresas não inovadoras, porém não foram encontradas diferenças entre esses grupos de empresas quanto à capacidade de aquisição. Provavelmente tal resultado seja proveniente das especificidades da amostra, a qual é composta apenas por empresas que já interagem, ou seja, que já fizeram esforços de aproximação com grupos de pesquisa e conhecimento relevantes (i.e. possuem capacidades de aquisição mais desenvolvidas).

A segunda análise é inédita, tanto teórica quanto empiricamente, e busca relacionar as dimensões da CA com os canais utilizados pelas empresas na interação com universidades. Foram analisados quatro canais, classificados como: tradicional; consultoria; pesquisa conjunta; empreendedor (ver Quadro 1). Identificou-se que quase a totalidade de empresas da amostra utilizava o canal tradicional, o que 
era esperado, dado estudos anteriores (COHEN; NELSON; WALSH, 2002). Porém, isso exigiu que os testes de média fossem realizados apenas entre as 21 empresas que utilizam esse canal.

Sobre o canal de consultoria, observou-se que empresas que o utilizam possuem maior capacidade de assimilação, enquanto as empresas que utilizam pesquisa conjunta apresentam maiores capacidades de aquisição e exploração. O primeiro canal demanda insumos menos sofisticados e estaria relacionado com objetivos de curto prazo (ARZA, 2010) e com a busca de conhecimentos mais próximos ao que a empresa já possui (BURCHART, 2011), exigindo, portanto, apenas capacidades de assimilação e não de transformação (TODOROVA; DURISIN, 2007). Já o segundo exigiria esforços de ambas as partes e estaria relacionado com objetivos de longo prazo, como a busca por inovações. Duas interpretações são possíveis. Por um lado, a pesquisa conjunta pode ter permitido à empresa construir uma rede de contatos que facilita sua aquisição de conhecimentos externos (maior capacidade de aquisição), além de ter auxiliado a empresa na redefinição de suas rotinas e competências (i.e capacidade de exploração). Por outro lado, esse canal pode demandar maiores capacidades de aquisição - para definir objetivos e identificar conhecimento importante para estabelecer tal parceira - e a empresa pode ter buscado uma pesquisa conjunta justamente por já possuir maior capacidade para explorar o conhecimento proveniente desse canal bidirecional. Ou seja, não se pode inferir uma causalidade única na relação entre CA e canais. A análise de qual causalidade predomina é uma agenda futura de pesquisa.

Já para as empresas que utilizam o canal empreendedor, não foram observadas diferenças, em todas as dimensões da CA, entre quem utiliza e quem não o utiliza. Tal fato pode ser explicado pela maior similaridade de conhecimentos, sendo que CA potencial não precisa ser elevada devido ao fato de as empresas estarem muito próximas à universidade e aos pesquisadores, recebendo a supervisão direta destes, enquanto a CA realizada ainda estaria sendo desenvolvida.

Tais resultados possuem limitações. Primeiramente, as empresas da amostra já interagirem com grupos das áreas de engenharia. Estas áreas se caracterizam por uma proximidade maior entre pesquisa básica e aplicada (CAROLO, 2011) e pela possibilidade de transferência de conhecimentos mais próximos à base de conhecimento da empresa, facilitando a identificação e absorção desse conhecimento. Em segundo lugar, a base de dados é relativamente pequena, exigindo estudos mais amplos e que abarquem mais setores e áreas do conhecimento.

Cabe também destacar a importância de mais estudos nesta temática aprofundando as especificidades da CA em países em desenvolvimento. Os resultados encontrados sugerem o desempenho de outro papel da universidade: não apenas como fonte externa de oportunidades tecnológicas, como observado nos países desenvolvidos (KLEVORICK et al., 1995), mas contribuintes para avanços tecnoló- 
gicos das empresas, ao complementarem a solução de gargalos produtivos, abarcando, pois, as oportunidades tecnológicas oriundas das "trajetórias naturais" das empresas.

Tal temática de estudo mostra-se relevante por permitir uma compreensão mais ampla das características da IUE, por meio dos seus canais, e da dinâmica inovativa das firmas que interagem, por meio da sua capacidade de absorção (e suas diferentes dimensões). Compreender qual a relação entre determinados canais da IUE com a CA da firma permite pensar em competências necessárias de acordo com tipos de IUE e possíveis resultados inovadores para a empresa, o que é fundamental para elaboração de políticas públicas e privadas com vistas a incrementar a competitividade das firmas.

\section{Referências}

ARZA, V. Channels, benefits and risks of public-private interactions for knowledge transfer: conceptual framework inspired by Latin America. Science and Public Policy, v. 37, n. 7, p. 473-484, ago. 2010.

BISHOP, K.; D'ESTE, P.; NEELY, A. Gaining from interactions with universities: multiple methods for nurturing absorptive capacity. Research Policy, v. 40, n. 1, p. 30-40, Feb. 2011.

BITTENCOURT, P.; GIGLIO, R. An empirical analysis of technology absorption capacity of the Brazilian industry. Cepal Review, n. 111, p. 175-190, Dec. 2013.

BRUNDENIUS, C.; LUNDVALL, B.; SUTZ, J. The role of universities in innovation systems in developing countries: developmental university systems - empirical, analytical, and normative perspectives. In: LUNDVALL, B. et al. (Ed.). Handbook of innovation systems and developing countries: building domestic capabilities in a global setting. Cheltenham: Edward Elgar Publishing, 2009.

BURCHARTH, A. L. L. A. What drives the formation of technological cooperation between university and industry in less- developed innovation systems ? Evidence from Brazil. Revista Brasileira de Inovação, v. 10, n. 1, p. 101-128, 2011.

CAMISÓN, C.; FÓRES, B. Knowledge absorptive capacity: new insights for its conceptualization and measurement. Journal of Business Research, v. 63, n. 7, p. 707-715, July 2010.

CAROLO, M.D. O impacto da interação universidade-empresa na produtividade dos pesquisadores: uma análise dos docentes coordenadores de projetos com apoio da Petrobrás. 2011. 87 f. Dissertação (Mestrado em Economia Aplicada) - Faculdade de Economia, Administração e Contabilidade, São Paulo, 2011.

CASTRO, P. G.; TEIXEIRA, A. L. S.; LIMA, J. E. A relação entre os canais de transferência de conhecimento das universidades/IPPs e o desempenho inovativo das firmas no Brasil. Revista Brasileira de Inovação, Campinas, v. 13, n. 2, p. 345-369, jul-dez. 2014.

CHEN, C. The effects of knowledge attribute, alliance characteristics, and absorptive capacity on knowledge transfer performance. RED Management, v. 34, n. 3, p. 311-321, June 2004. 
COHEN, W. M.; NELSON, R. R.; WALSH, J. P. The influence of public research on industrial RED. Management Science, v. 48, n. 1, p. 1-23, Jan. 2002.

COHEN, W. M.; LEVINTHAL, D. A. Absorptive capacity : a new perspective on learning and innovation. Administrative Science Quarterly, v. 35, n. 1, p. 128-152, 1990.

. Fortune favors the prepared firm. Management Science, v. 40, n. 2, p. 227-251, Feb. 1994.

. Innovation and learning: the two faces of RED. The Economic Journal, v. 99, n. 397, p. 569-596, Sept. 1989.

FUENTES, C.; DUTRÉNIT, G. Best channels of academia-industry interaction for long-term benefit. Research Policy, v. 41, n. 9, p. 1666-1682, Nov. 2012.

. Geographic proximity and university-industry interaction: the case of Mexico. The Journal of Technology Transfer, v. 41, n. 2, p. 329-348, 2014.

DUTRÉNIT, G.; ARZA, V. Channels and benefits of interactions between public research organizations and industry: comparing four Latin American countries. Science and Public Policy, v. 37, n. 7, p. 541-553, Aug. 2010.

EOM, B.; LEE, K. Modes of knowledge transfer from PROs and firms performance: the case of Korea. Seoul Journal of Economics, Seoul, v. 22, n. 4, p. 499-528, Dec. 2009.

ETZKOWITZ, H. et al. The future of the university and the university of the future: evolution of ivory tower to entrepreneurial paradigm. Research Policy, v. 29, n. 2, p. 313-330, 2000.

EUN, J. China's horizontal university-industry linkages: where from and where to. Seoul Journal of Economics, v. 22, n. 4, p. 445-466, Dec. 2009.

FERNANDES, A.C et al. Academy-industry links in Brazil: evidence about channels and benefits for firms and researchers. Science and Public Policy, v. 37, n. 7, p. 485-498, Aug. 2010.

FLATTEN, T. C. et al. A measure of absorptive capacity: scale development and validation. European Management Journal, v. 29, v. 2, p. 98-116, Apr. 2011.

GALINA, S. V. R.; ALVES, M. F. R.; VICENTIN, F. O. P. Alliance impact on absorptive capacity: analysis of brazilian ICT companies. In: ANNUAL CONFERENCE OF ACADEMY OF INTERNATIONAL BUSINESS, 6., 2016, São Paulo. Anais... São Paulo: AIBLAT, 2016.

HAIR, J. F et al. Análise multivariada de dados. 5. ed. Porto Alegre: Bookman, 2005.

JIMÉNEZ-BARRIONUEVO, M. M. et al. Validation of an instrument to measure absorptive capacity. Technovation, v. 31, n. 5-6, p. 190-202, 2011.

JOSEPH K. J.; ABRAHAM, V. University-industry interactions and innovation in India: patterns, determinants, and effects in selected industries. Seoul Journal of Economics, v. 22, n. 4, p. 467-498, Dec. 2009.

KLEVORICK, A. K. et al. On the sources and significance of inter-industry differences in technological opportunities. Research Policy, v. 24, n. 2, p. 185-205, Mar. 1995. 
LINTING, M. et al. Nonlinear principal components analysis: introduction and application. Psychological Methods, v. 12, n. 3, p. 336-358, 2007.

LUNDVALL, B. A. The university in the learning economy. Aalborg: DRUID, 2002. (Working Paper, n. 02-06).

MANGEMATIN, V.; NESTA, L. What kind of knowledge can a firm absorb? International Journal of Technology Management, v. 37, n. 3, p. 149-172, 1999.

MEYER-KRAHMER, F.; SCHMOCH, U. Science-based technologies: university industry interactions in four fields. Research Policy, v. 27, n. 8, p. 835-851, 1998.

MEULMAN, J. J.; VAN DER KOOIJ, A. J.; HEISER, W. J. Principal components analysis with nonlinear optimal scaling transformations for ordinal and nominal data. In: KAPLAN, D. (Ed.). The sage handbook of quantitative methodology for the social sciences. Thousand Oaks: SAGE Publications, 2004.

MOWERY, D. C.; SAMPAT, B. N. Universities in national innovation systems. In: FAGERBERG, J.; MOWERY, D. C.; NELSON, R. R. (Ed.). The Oxford handbook of innovation. New York: Oxford University Press, 2006.

MUROVEC, N.; PRODAN, I. Absorptive capacity, its determinants, and influence on innovation output: cross-cultural validation of the structural model. Technovation, v. 29, n. 12, p. 859-872, 2009.

NEGRI, F. Determinantes da capacidade de absorção das firmas brasileiras: qual a influência do perfil da mão-de-obra. In: NEGRI, J. A.; NEGRI, F.; COELHO, D. (Ed.) Tecnologia, Exportação e Emprego. 1. ed. Brasília, DF: Instituto de Pesquisa Econômica Aplicada, 2006. p.101-122.

NELSON, R. Capitalism as an engine of progress. Research Policy, v. 19, n. 3, p. 193-214, June 1990.

Institutions supporting technical advance in industry. The American Economic Review, v. 76, n. 2, p. 186-189, 1986.

ROSA, A. C. Capacidade absortiva de empresas que possuem interação com universidades. 2013. 162 f. São Leopoldo. Dissertação (Mestrado em Economia) - Programa de PósGraduação em Economia, Universidade do Vale do Rio dos Sinos, São Leopoldo, 2013.

ROSENBERG, N. On Technological Expectations, Economic Journal, v. 86, n. 343, p. 523$535,1976$.

. Por dentro da caixa preta: tecnologia e economia. Campinas: Unicamp, 2006.

Scientific instrumentation and university research? Research Policy, v. 21, n. 4, p. 381-390, 1992.

ROSENBERG, N.; NELSON, R. American university and technical advance in industry. Research Policy, v. 23, n. 3, p. 323-348, May 1994. 
SUZIGAN, W.; ALBUQUERQUE, E. M.; CARIO, S. F. (Org.). Em busca da inovação: interação universidade-empresa no Brasil. Belo Horizonte: Autêntica, 2011.

TODOROVA, G; DURISIN, B. Absorptive capacity: valuing a reconceptualization. Academy of Management Review, v. 32, n. 3, p. 774-786, 2007.

BOSCH, F. A. J.; VOLBERDA, H. W.; BOER, M. Coevolution of Firm absorptive capacity and knowledge environment: Organizational forms and combinative capabilities. Organization Science, v. 10, n. 5, p. 551-568, 1999.

VEGA-JURADO, J.; GUTIÉRREZ-GRACIA, A.; FERNÁNDES-de-LUCIO, I. Analyzing the determinants of firm 's absorptive capacity: beyond REDD. RE् D Management, v. 38, n. 4, p. 392-405, 2008.

VERSIANI, A. F. et al. Mensuração da capacidade absortiva: até que ponto a literatura avançou? In: ENCONTRO DA ASSOCIAÇÃO NACIONAL DE PROGRAMAS DE PÓSGRADUAÇÃO EM ADMINISTRAÇÃO, 34., 2010, Rio de Janeiro. Anais... Rio de Janeiro: ANPAD, 2010.

ZAHRA, S. A.; GEORGE, G. Absorptive capacity: a review, reconceptualization, and extension. Academy of Management Review, v. 27, n. 2, p. 185-203, 2002. 


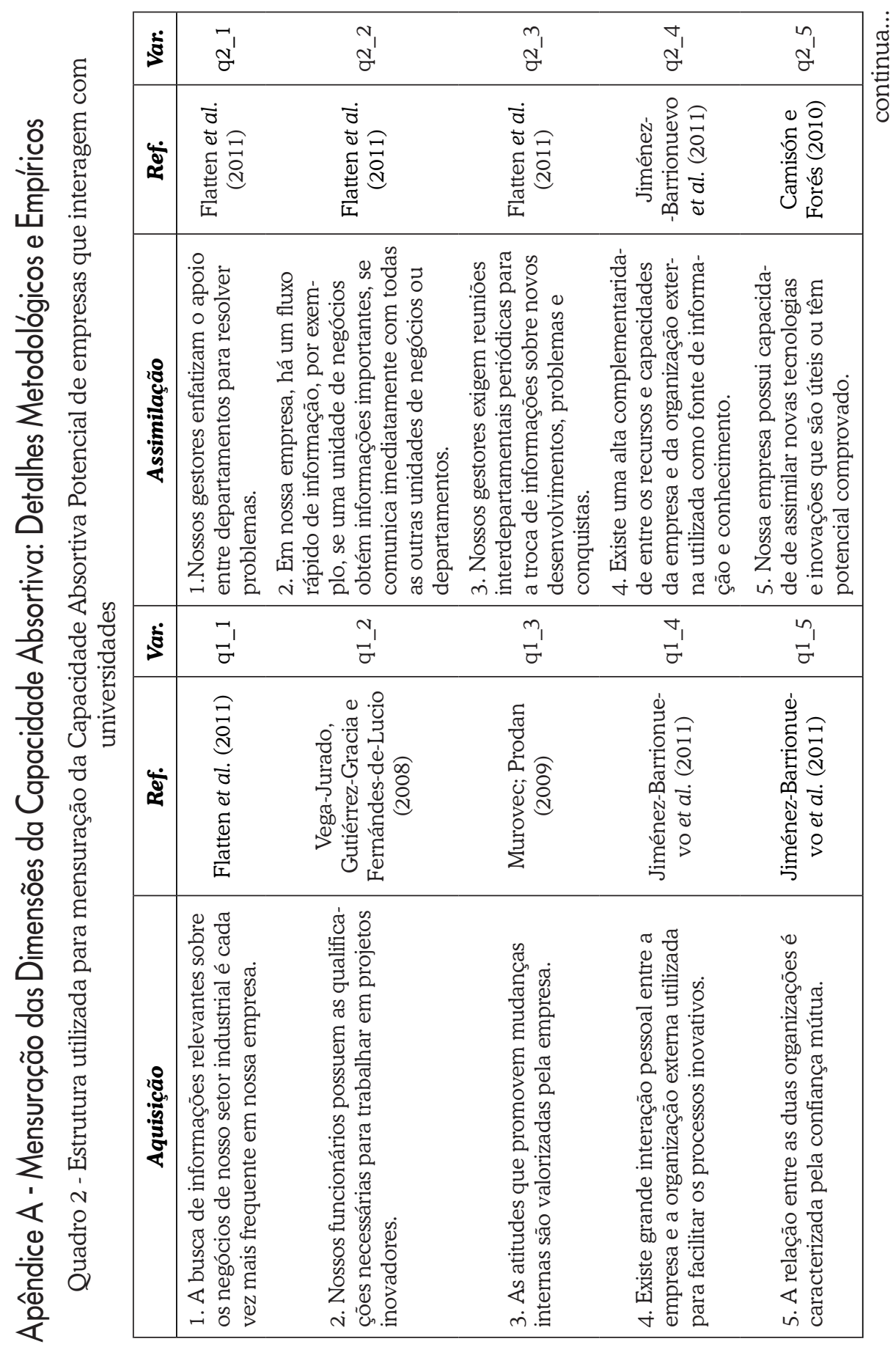




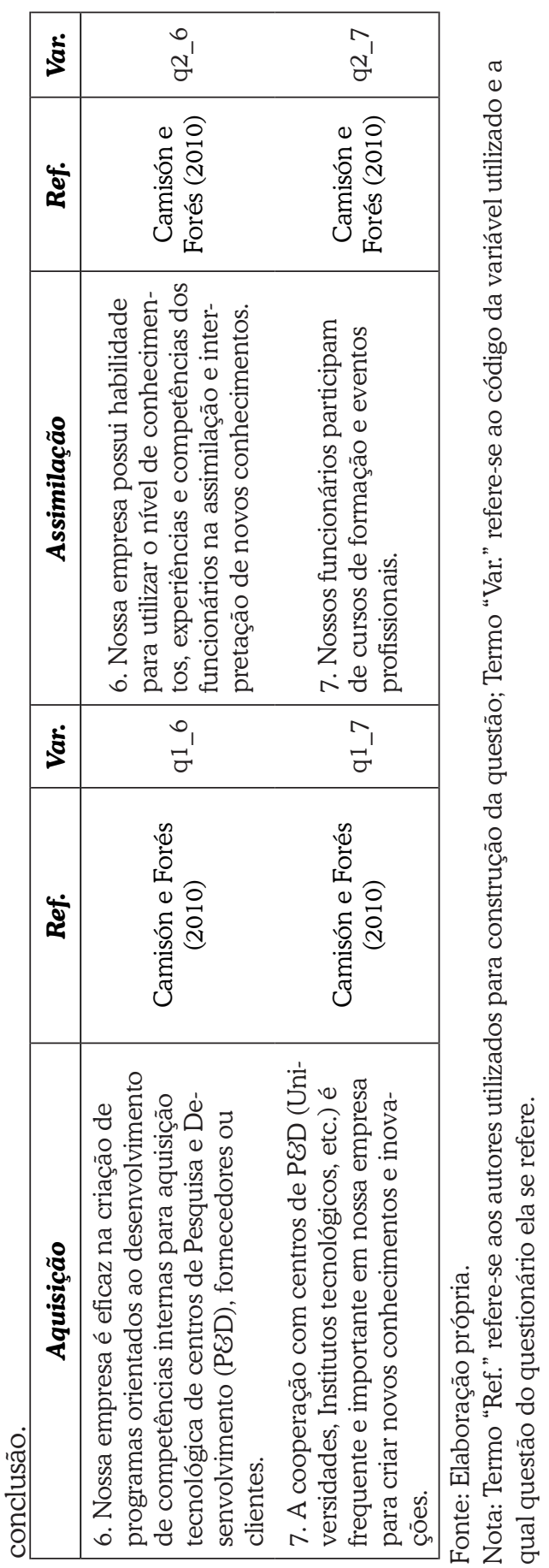




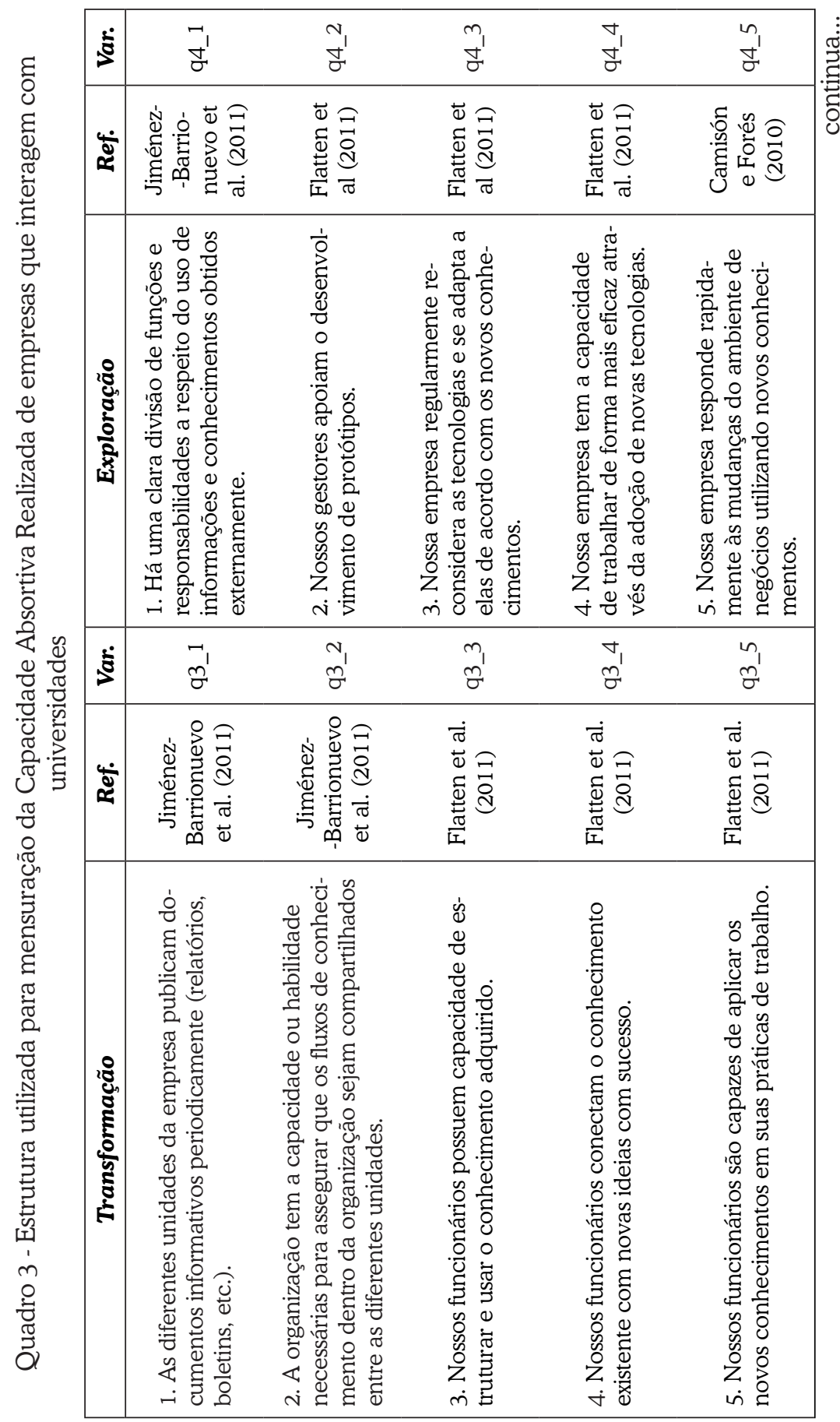




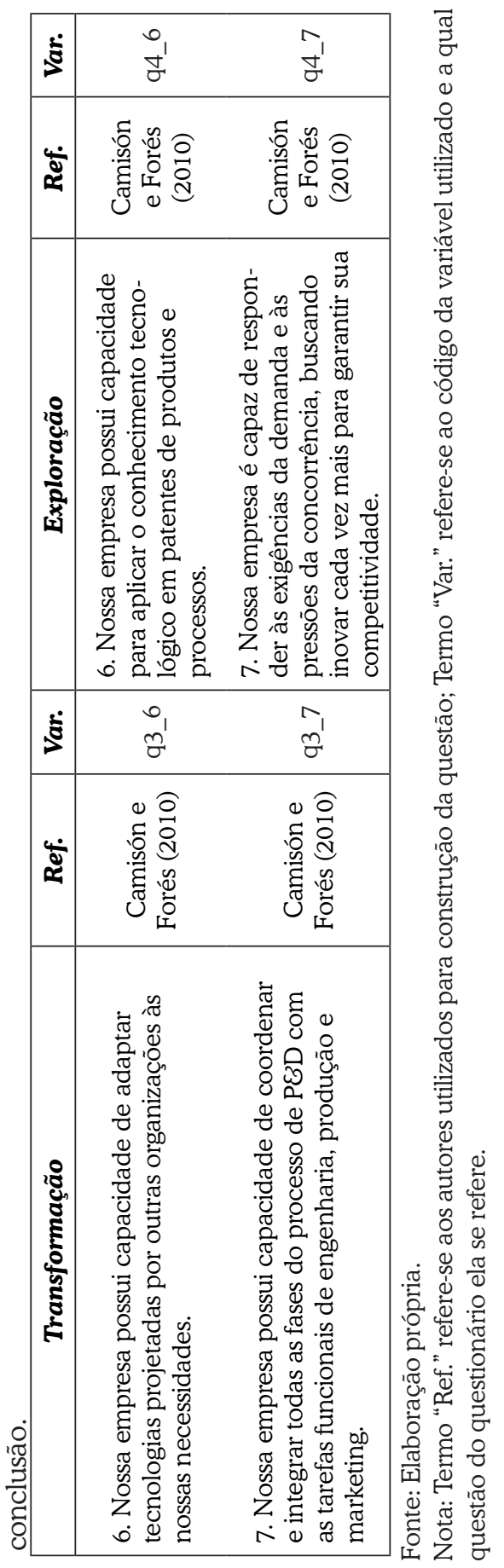


Tabela 6 - Components Loadings para o indicador de Capacidade de Aquisição

\begin{tabular}{c|c}
\hline Variável & Components Loadings \\
\hline q1_1 & 0,895 \\
q1_2 & 0,662 \\
q1_3 & 0,921 \\
q1_4 & 0,759 \\
q1_5 & 0,606 \\
q1_6 & 0,75 \\
q1_7 & 0,444 \\
\hline
\end{tabular}

Fonte: Elaboração própria.

Tabela 7 - Components Loadings para o indicador de Capacidade de Assimilação

\begin{tabular}{c|c}
\hline Variável & Components Loadings \\
\hline q2_1 & 0,986 \\
q2_2 & 0,787 \\
q2_3 & 0,904 \\
q2_4 & 0,793 \\
q2_5 & 0,986 \\
q2_6 & 0,987 \\
q2_7 & 0,556 \\
\hline
\end{tabular}

Fonte: Elaboração própria.

Tabela 8 - Components Loadings para o indicador de Capacidade de Transformação

\begin{tabular}{c|c}
\hline Variável & Components Loadings \\
\hline q3_1 & 0,401 \\
q3_2 & 0,469 \\
q3_3 & 0,987 \\
q3_4 & 0,988 \\
q3_5 & 0,993 \\
q3_6 & 0,985 \\
q3_7 & 0,987 \\
\hline
\end{tabular}

Fonte: Elaboração própria. 
Tabela 9 - Components Loadings para o indicador de Capacidade de Exploração

\begin{tabular}{c|c}
\hline Variável & Components Loadings \\
\hline q4_1 & 0,896 \\
q4_2 & 0,956 \\
q4_3 & 0,896 \\
q4_4 & 0,937 \\
q4_5 & 0,665 \\
q4_6 & 0,444 \\
q4_7 & 0,956 \\
\hline
\end{tabular}

Fonte: Elaboração própria.

Recebido em: 11/07/2015. Aceito em: 08/08/2017. 